\title{
Induced Pluripotent Stem Cell Technology and Direct Conversion: New Possibilities to Study and Treat Parkinson's Disease
}

\author{
Reinhard Roessler • Erik Boddeke - Sjef Copray
}

Published online: 13 April 2012

(C) The Author(s) 2012. This article is published with open access at Springerlink.com

\begin{abstract}
Recent developments in in vitro disease modeling and regenerative medicine have placed induced pluripotent stem cells (iPSCs) in the center of attention as a unique source to study Parkinson's disease. After only 5 years of intensive research, human iPSCs can be generated without viral integration and under xeno-free conditions. This, combined with increasingly sophisticated methods to differentiate iPSCs into functional dopaminergic (DA) neurons, led us to recapitulate the most important findings concerning the use of iPSC technology as a prospective tool to treat symptoms of Parkinson's disease as well as to obtain insight in disease related cell pathogenesis. Moreover, we touch upon some of the latest discoveries in which patient-derived autologous DA neurons come into even more direct reach thanks to a method that allows transdifferentiation of fibroblasts into DA neurons.
\end{abstract}

Keywords Induced pluripotent stem cells · Parkinson's disease - Dopaminergic neurons - In vitro disease modeling · Cell based therapy $\cdot$ Transdifferentiation

\section{The Rise of Induced Pluripotency}

The discovery of induced pluripotent stem cells quickly developed into one of the most competitive and most sophisticated research areas in biology. In 2006, a key study by the group of Shinya Yamanaka showed for the first time that somatic cells, such as murine embryonic fibroblasts

R. Roessler $\cdot$ E. Boddeke $\cdot$ S. Copray $(\bowtie)$

Department of Neuroscience, Medical Physiology,

University Medical Center Groningen, University of Groningen,

A.Deusinglaan 1,

9713 AV, Groningen, The Netherlands

e-mail: j.c.v.m.copray@umcg.nl
(MEFs), could be reprogrammed to a pluripotent, embryonic stem (ES) cell-like state [1]. This epigenetic reprogramming event in fibroblasts was driven by viral delivery of four transcription factors (hereafter referred to as 'Yamanaka factors'), namely Oct4, Sox2, Klf4 and cMyc. It became clear that when these genes successfully integrated into the genome of a host cell and expression occurred in an optimal stochastic manner, the virus transfected cell changes from a differentiated somatic cell into a pluripotent stem cell, which in turn is able to differentiate into every cell type of the body. Shortly after this groundbreaking discovery several other groups confirmed and reported the generation of iPSCs. Procedural optimization steps have been undertaken thereafter for example by using a more suitable selection marker for the reprogrammed induced pluripotent stem cells Oct4 or Nanog [2] instead of Fbx15 (used by the Yamanaka group) or even by identifying iPSC colonies merely on their morphology instead of the use of genetically modified fibroblasts as starting material [3]. IPSCs generated by this epigenetic reprogramming process have been characterized and identified as truly fulfilling the criteria for pluripotency within a very short time span. Thus, iPSCs were not only able to differentiate into cell types from all three germ layers (mesoderm, endoderm and ectoderm) and to contribute to embryo formation after injection in a blastocyst (chimeric mice), they could also contribute to the germ line in such a setup. Moreover, they formed teratomas after subcutaneous injection or subcapsular implantation in the testis or kidney $[4,5]$. Last but not least, as one of the most stringent criteria for pluripotent cells, iPSCs have been injected in a tetraploid blastocyst, which was subsequently implanted in a surrogate mother mouse, where they gave rise to so called 'all-iPS mice', viable mice that exclusively originated from the implanted iPSCs, via a process called tetraploid complementation $[5,6]$. 
The next major step in iPSC research was the discovery that also human somatic cells could be reprogrammed into iPSCs using a similar approach and with similar properties as mouse iPSCs $[7,8]$.

Due to the extremely rapid development in this particular research field, iPSCs became highly interesting tools for in vitro disease modeling but also for potential application in regenerative medicine. However, the reprogramming procedure itself was bearing a crucial and very undesirable component. IPSCs so far were generated by use integrating viruses that intrinsically modified the genome of the host cells. Especially the integration of oncogenes such as cMyc and Klf4 would not be acceptable for any clinical application of iPSC-derived cells or tissues. In order to avoid this hurdle, several methods have been tested to circumvent viral integration events. First attempts were directed to reduce the number of integrating proviruses e.g. by eliminating Myc transduction [9], but also the generation of iPSCs with nonintegrating adenoviruses and temperature sensitive Sendai viruses has been tested and proven possible [10, 11]. In a next logical follow up step, the use of viruses has been abandoned completely by utilization of direct repeated transfection with 'Yamanaka factor' containing plasmids [12] or piggyback transposons [13]. Another interesting approach is the use of microRNAs (miRs) to drive induction of pluripotency. Anokye-Danso et al. [14] showed that two specific miRs (miR302 and miR367) are sufficient to induce pluripotency in mouse and human somatic cells without forced expression of exogenous transcription factors [14]. Even more towards a safe clinical use is the induction of pluripotency with RNA molecules that code for the four 'Yamanaka factors' [15]. Eventually it has been shown that iPSCs can also be generated by direct Oct4-, Sox2-, Klf4and cMyc- protein delivery to human fibroblasts [16].

In general it seems that technical safety issues that previously hampered the use of iPSCs for a wide variety of clinical applications are about to be solved. In the scope of this review these developments are particularly interesting for the in vitro generation of iPSC derived DA neurons (Fig. 1).

\section{Mouse iPSCs as Crucial Model System}

Mouse as well as human iPSCs have been shown to be capable to differentiate into varying clinically relevant cell types, such as cardiomyocytes [17, 18], hepatocytes [19], hematopoetic progenitors [20], oligodendrocytes [21] and specific subtypes of neurons $[22,23]$. In particular, iPSC-derived DA neurons appear to be a very interesting, clinically relevant cell type (for overview of key studies see Table 1). First, they might serve as novel easily accessible autologous source for cell replacement. Many studies, starting in the 1980s, have already demonstrated that the consequences of the specific loss of midbrain DA neurons in the substantia nigra pars compacta $(\mathrm{SNc})$, the hallmark of Parkinson's disease, can be partly obviated by the intrastriatal implantation of extrinsic (heterologous) abortion-derived fetal human DA neurons [24-26]. Although this approach itself appeared to be successful, major practical and ethical concerns related to the use of this fetal human graft source were unbridgeable and made this strategy not feasible for the clinic [27, 28].

Secondly, iPSC derived DA neurons provide a unique tool to investigate cell pathogenic mechanisms in detail (e.g. the role of $\alpha$-synuclein or LRRK2, etc.), particularly when the iPSCs are generated from patients with a hereditary form of Parkinson's disease [29, 30].

Before the iPSC technology entered the playground, DA neuron differentiation has been extensively studied for embryonic stem cells (ESCs) and neural stem cells (NSCs), either derived from ESCs [31, 32] or primary isolated [33, 34]. In order to improve in vitro generation of DA neurons derived from ESCs protocols have been developed that enhance DA differentiation. Early approaches involved the use of stromal feeder layers (such as MS5 or PA6 cells) [35, 36]. Later, in order to avoid undefined factors, protocols have been established that employ small molecules and recombinant proteins which specifically inhibit BMP signaling pathway (dual inhibition of SMAD signaling) [37]. Recent studies provide evidence that derivation of floor plate cells (the floor plate is a crucial organizing structure in the developing embryo, located along the ventral midline) from pluripotent stem cells, by early supplementation with high concentrations of sonic hedgehog and induction of canonical Wnt signaling by small molecules, drastically improves the quantity and quality of subsequently generated DA neurons [38, 39].

Based on established methods for in vitro differentiation of DA neurons efficient protocols for dopaminergic differentiation of iPSCs have been developed. One of the first studies by Wernig et al. [22] showed successful generation of DA neurons derived from mouse iPSCs [22]. These cells showed some specific DA marker expression, such as the transcription factors Nurr1, Pitx3 and the enzyme tyrosine hydroxylase (TH). Furthermore, they revealed typical neuron-like electrophysiological properties and they functionally integrated in a rat model for PD after transplantation. However, the number of DA neurons that could be generated did not exceed $4 \%$ of the starting iPSC population, indicating that most of the cells that developed with that differentiation procedure had nonDA characteristics. While the study provided the proof of principle for treating PD symptoms with iPSC derived DA neurons in an animal model, various important issues were not or could not be addressed. Firstly, since only a minority of grafted iPSC derived cells were DA neurons, it can be questioned what the effect was of the vast majority of other cell types in the graft; it is clear that some kind of purification step is required. Secondly, in view of the exceptional origin of the 
iPSC technology

Transdifferentiation

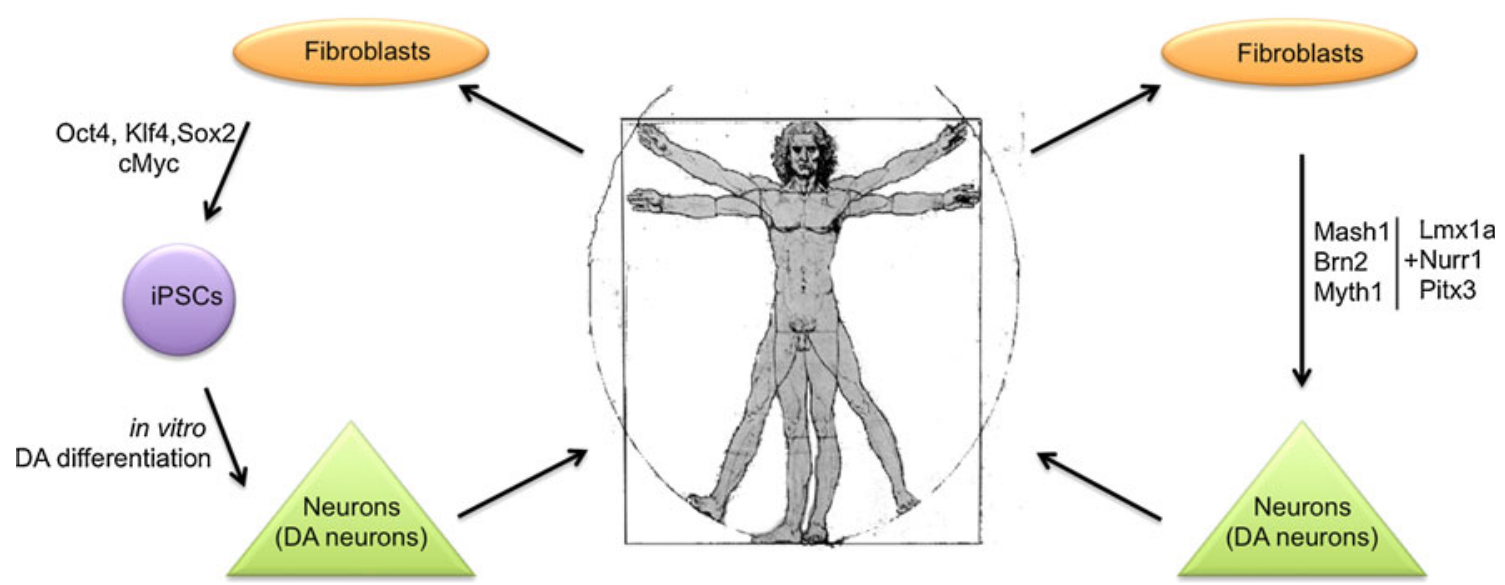

Fig. 1 Schematic comparison between iPSC technology and transdifferentiation to generate DA neurons in vitro. IPSC technology requires a forced expression/induction (either by viral transduction, RNA or protein transfection) of Oct4, Klf4, Sox 2 and cMyc. Recent DA differentiation protocols provide robust yields of neurons highly

DA neurons, characterization of the iPSC derived DA neurons and assessment of the completeness and stability of differentiation should not only be based on a set of general DA markers and electrophysiological characteristics, but should also contain extensive genetic and epigenetic screening. The challenge for a more comprehensive study of epigenetic and genetic characteristics of iPSC derived DA neurons mainly lies in the necessity to generate a cell population that allows purification based on a highly specific midbrain DA marker. Earlier studies reported the generation of ESC lines with specific heterozygous GFP knock-in modification in the dopamine transporter (DAT) locus and the Pitx3 locus [40, resembling DA neuron characteristics. Directly converted neurons are not derived from a pluripotent intermediate, which minimizes undesired differentiation potential and risks for teratoma formation. DA-like neurons generated so far however show only very limited resemblance with primary midbrain DA neurons

41]. Both genes code for specific DA markers. Pitx3 is a transcription factor specifically expressed in $\mathrm{mDA}$ neurons, that interacts with Nurr1 and is crucially involved in differentiation and maintenance processes for mDA neurons [42-45]. DAT is widely expressed in DA neurons and specifically indicates their maturation [46]. However, because of its general function in DA neurons (residing e.g. in the olfactory bulb or the ventral tegmental area) DAT cannot be considered as a selective marker for mDA neurons.

Our group has used Pitx3-GFP knock-in mice (kindly provided by Prof. M. Smidt, SILS, University of Amsterdam) for the generation of iPSC lines. The Pitx3-GFP knock-in

Table 1 Key studies for in vitro generation of DA neurons/iDA neurons from pluripotent stem cells and somatic cells (trans-differentiation), respectively

\begin{tabular}{|c|c|c|c|c|}
\hline Species & Viral integration & Pluripotent stem cells & Characterization & Reference \\
\hline Mouse & Yes & iPSCs & DA markers, electrophys.properties, functional integration & {$[22]$} \\
\hline Human & No (direct protein delivery) & human iPSCs & $\begin{array}{l}\text { DA markers, electrophys. Properties, DA release, } \\
\text { functional integration }\end{array}$ & {$[51]$} \\
\hline Human & Yes(Cre-excised) & iPSCs (patient specific) & DA markers & {$[52]$} \\
\hline Human & Yes(Cre-excised) & iPSCs (patient specific) & DA markers, functional integration (6OHDA rats) & {$[53]$} \\
\hline Human & No (Sendai virus) & ESCs/iPSCs & $\begin{array}{l}\text { Floor plate based DA induction, DA gene expression profile, } \\
\text { electrophys. properties, functional integration }\end{array}$ & [39] \\
\hline Species & Viral integration & Trans-differentiation & Characterization & Reference \\
\hline Mouse & Yes & transdiff. fibroblasts iDA neurons & $\begin{array}{l}\text { DA markers (TH selection) electrophys.properties, DA } \\
\text { release, global gene expression (TH sorted), } \\
\text { functional integration }\end{array}$ & {$[62]$} \\
\hline Mouse & Yes & transdiff. fibroblast iDA neurons & $\begin{array}{l}\text { DA markers (Pitx3 selection), electrophys.properties, DA } \\
\text { release, selected gene expression (Pitx3 sorted), } \\
\text { functional integration }\end{array}$ & [69] \\
\hline
\end{tabular}


feature allowed us selective isolation, identification and purification of primary embryonic and postnatal $\mathrm{mDA}$ neurons as well as of DA neurons that were obtained via differentiation of the iPSCs (see Fig. 2). This approach enabled us to perform an extensive comparison of iPSC-derived DA neurons with primary mDA neurons (including varying developmental stages) as far as their genetic and epigenetic profiles are concerned. We particularly focused on DNA methylation, since reprogramming of somatic cells towards pluripotent cells and subsequent differentiation into DA neurons must entail massive changes in DNA methylation patterns in specific genomic loci [47-50]. This type of characterization, which was based on the ability to analyze purified Pitx3-GFP DA neurons, enabled us to determine a close similarity in terms of DNA methylation patterns between iPSC-derived DA neurons and primary DA neurons and provides novel insight in cell type specific de novo methylation during in vitro differentiation (Roessler et al., manuscript in preparation). Before human iPSC-derived DA neurons might serve as tool for future cell replacement approaches such detailed in depth-studies will certainly be required in order to assure their clinically safe status as well as their bona fide characteristics. It will however remain difficult to directly compare human iPSC-derived DA neurons tor their primary counterpart.

\section{Human iPSCs to Study and Treat PD}

Clinical application of iPSC-derived DA neurons for treating Parkinson's disease is still a distant option. All the aforementioned issues concerning the clinically safe use of iPSCs as well as the incomplete characterization of in vitro generated DA neurons form prominent roadblocks that remain to be cleared. A recent study provides evidence that human iPSCs completely free of proviruses (these hiPSCs were generated by direct protein delivery) are efficiently capable to differentiate towards functional DA neurons [51]. Such patient-derived iPSCs will provide a valuable tool for possible future cell based therapy approaches.

Soldner et al. [52] were the first to generate human iPSCs (hiPSCs) cells from patients with idiopathic PD [52]. Their study showed that indeed reprogramming factor-free iPSCs could be generated from PD patients using Cre-recombinase excisable viral constructs. Moreover, those patient-specific iPSCs could be differentiated in tyrosine hydroxylase (TH)expressing neurons. In a follow-up study, PD patient iPSCderived $\mathrm{TH}$ expressing neurons have been transplanted in a PD rat model (6-OHDA), where they reduced specific neurotoxin-induced asymmetric motor behavior [53]. These studies demonstrate the capability of hiPSCs to differentiate into functional neurons that improve PD symptoms associated with reduced dopamine signaling in the striatum. However, more extensive research needs to be done to further characterize patient-specific iPSC derived DA neurons in terms of the completeness and stability of their differentiated state. For that, global gene expression studies but also, as mentioned above, in-depth studies of epigenetic characteristics such as DNA methylation and histone modifications are required before clinical application will come within reach.

Regarding the use of patient-specific iPSC-derived DA neurons as in-vitro PD model, it should be considered that $\mathrm{PD}$ is in general a late onset disease, which affects patients after decades of latent disease progress. Therefore, it may be quite challenging to model PD in vitro. Slowly developing molecular changes such as $\alpha$-synuclein aggregation in patient derived DA neurons might not be detectable in cell culture that at best can be maintained for a few month.
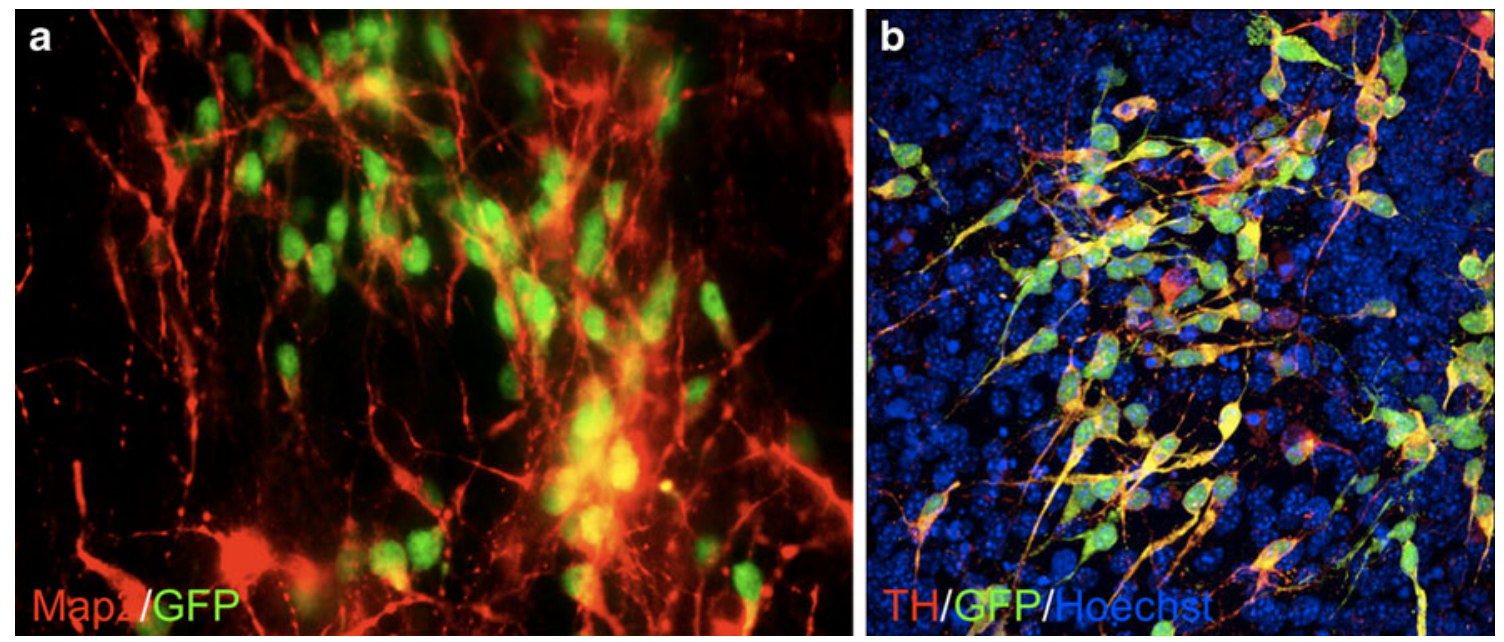

Fig. 2 Pitx3-GFP iPSC derived mDA neurons show co-expression of transgenic GFP (Pitx $3^{\mathrm{gfp} /+}$ ) and Map2 (a) as well as tyrosine hydroxylase (TH) (b). Confocal microscopy (b) revealed that most of the
Pitx3 expressing cells also express TH. However TH positive cells do not always show Pitx 3 expression 
Moreover, genetic variations intrinsic to patient-specific iPSCs could complicate disease modeling since it will be literally impossible to generate experimentally defined conditions. A very interesting approach in that respect is a technology known as 'genome editing', employing zinc finger nucleases (ZFNs) to site-specifically target a disease relevant gene. Soldner et al. [54] used ZFNs in patientspecific iPSCs to exclusively manipulate a point mutation site in the $\alpha$-synuclein gene known to be key in rare forms of familial PD [54]. Mutations in $\alpha$-synuclein at specific sites (e.g.: A53T; E46K or A30P) lead to the formation of Lewy bodies, which are inclusions present in affected DA neurons (for reviews on $\alpha$-synuclein and Lewy bodies see e.g. $[55,56])$. In this study by Soldner and colleagues [54] these mutations have been addressed with genome editing aiming either at correction of a specific mutation (e.g. in PD patient specific hiPSCs) or vice versa at generation of a mutation (e.g. in wild-type ES cells) in order to study cell pathogenic consequences of such disease relevant modifications.

Even though, DA neurons generated from human iPSCs do not easily allow purification as indicated for transgenic mouse iPSC-derived DA neurons, a thorough characterization is extremely crucial. Conceivable approaches also involve genome editing. ZFNs (as described above) and transcription activator-like effector nucleases (TALENs) have been used to genetically engineer human iPSCs that contain the GFP coding sequence (either 2A-eGFP or eGFP) in the locus of the Pitx 3 gene $[57,58]$. As yet, however no study showed the purification of Pitx3-GFP cells derived from ZFNs- or TALENs-modified human iPSCs. Succeeding in such a purification step will certainly improve the possibility to study specific molecular modifications (e.g. mutations in the $\alpha$-synuclein- or LRRK2gene) and their consequences in affected cells. It might also allow to find changes in cells bearing disease relevant modifications before phenotypic (pathological) changes are detectable.

\section{Towards a Direct Patient Specific Cell Replacement Strategy}

Very recent studies report about the direct conversion or transdifferentiation of fibroblasts to neurons (see Fig. 1), avoiding a pluripotent 'in between-stage'. This approach, although in a yet premature phase, shows a highly interesting option to generate DA neurons, circumventing some of the most critical pitfalls of the iPSC technology. In 2010, researchers described the possibility to manipulate mouse fibroblasts by introducing three neurodevelopmental factors (Brn2, Ascl1 and Myth11) in such a way that they directly converted into neuronal cells, so called induced neurons, or
iNs [59]. Shortly after that, the same group reported the same achievement for human fibroblasts [60]. Both, mouse and human iNs showed expression of neuronal markers such as Tuj1, Map2, Tau and synapsin and revealed neuron-like electrophysiological properties.

In a more PD relevant approach two groups showed that the combination of the above mentioned iN factors combined with Lmx1a and FoxA2 [61] or a combination of Lmx1a and Nurr1 [62] in fibroblasts is sufficient to directly induce cells with DA neuronal characteristics, therefore called iDA neurons.

The combination of the three neurodevelopmental factors (BAM) with factors known to be crucially involved in the embryonic development of $\mathrm{mDA}$ neurons as well as for their beneficial effect for DA differentiation of ESCs [63-68] seem to specifically boost the transdifferentiation towards DA-like neurons. Even though these findings provide a proof of principle for the amazing possibility to directly transdifferentiate/convert somatic cells just by simple forced expression of a specific set of transcription factors, also for iDA neurons a very thorough characterization would be necessary before one could seriously consider their clinical application.

For a better understanding of to what extent iDA neurons are similar to primary midbrain DA neurons, the use of transgenic Pitx3-GFP mice, as described above for iPSCs, can be an adequate tool. Kim et al. [69] used tail tip fibroblasts from transgenic Pitx3-GFP mice for transdifferentiation experiments [69]. iDA neurons were isolated based on GFP expression and gene expression was compared to primary midbrain DA neurons (equally positive for Pitx3GFP). Comparison of a selected list of markers for DA neurons showed only limited similarities between iDA and primary DA neurons. However, Pitx3-GFP sorted iDA neurons showed dopamine release, acquired highly similar electrophysiological properties and showed functional integration in 6-OHDA lesioned mice.

Taken together, the possibility to directly convert somatic cells into neurons might provide a valuable tool to study diseases like PD in vitro. Besides, when issues such as the conversion efficiency and the not yet optimal genotypic and phenotypic characteristics are solved and improved, iDA neurons could provide a cell replacement tool as well.

\section{Concluding Remarks}

The full scope of iPSC-based technology in terms of in vitro disease modeling as well as in regenerative medicine becomes more and more apparent. This might in particular be the case for approaches to treat Parkinson's disease. We strongly believe that future research in this exciting field will provide much more details about disease-causing 
factors, at cellular as well as environmental level. In addition, a clinically safe generation of human iPSCs and the subsequent in vitro generation of patient specific DA neurons might provide realistic tools to replace lost DA neurons in PD patients. Last but not least the sheer possibility to generate specific DA neurons directly from patient fibroblasts opens up a completely new angle concerning cellular PD research.

Open Access This article is distributed under the terms of the Creative Commons Attribution License which permits any use, distribution, and reproduction in any medium, provided the original author(s) and the source are credited.

\section{References}

1. Takahashi, K., \& Yamanaka, S. (2006). Induction of pluripotent stem cells from mouse embryonic and adult fibroblast cultures by defined factors. Cell [Internet]. [cited 2011 Jul 15], 126(4), 66376. Available from: http://www.ncbi.nlm.nih.gov/pubmed/ 16904174

2. Wernig, M., Meissner, A., Foreman, R., et al. (2007). In vitro reprogramming of fibroblasts into a pluripotent ES-cell-like state. Nature [Internet] [cited 2011 Jun 11], 448(7151), 318-24. Available from: http://www.ncbi.nlm.nih.gov/pubmed/17554336.

3. Meissner, A., Wernig, M., Jaenisch, R. (2007). Direct reprogramming of genetically unmodified fibroblasts into pluripotent stem cells. Nature Biotechnology [Internet] [cited 2011 Jul 17], 25(10), 1177-81. Available from: http://www.ncbi.nlm.nih.gov/pubmed/ 17724450

4. Miura, K., Okada, Y., Aoi, T., et al. (2009). Variation in the safety of induced pluripotent stem cell lines. Nature Biotechnology [Internet] [cited 2011 Jun 10], 27(8), 743-5. Available from: http:// www.ncbi.nlm.nih.gov/pubmed/19590502.

5. Zhao, X-Y., Li, W., Lv, Z, et al. (2009). iPS cells produce viable mice through tetraploid complementation. Nature [Internet] [cited 2011 Jun 23], 461(7260), 86-90. Available from: http:// www.ncbi.nlm.nih.gov/pubmed/19672241.

6. Kang, L., Wang, J., Zhang, Y., Kou, Z., Gao, S. (2009). iPS cells can support full-term development of tetraploid blastocystcomplemented embryos. Cell Stem Cell [Internet] [cited $2011 \mathrm{Jul}$ 17], 5(2), 135-8. Available from: http://www.ncbi.nlm.nih.gov/ pubmed/19631602.

7. Takahashi, K., Tanabe, K., Ohnuki, M., et al. (2007). Induction of pluripotent stem cells from adult human fibroblasts by defined factors. Cell [Internet] [cited 2011 Jul 18], 131(5), 861-72. Available from: http://www.ncbi.nlm.nih.gov/pubmed/18035408.

8. Park, I-H., Zhao, R., West, J. A., et al. (2008). Reprogramming of human somatic cells to pluripotency with defined factors. Nature [Internet] [cited 2011 Jul 15], 451(7175), 141-6. Available from: http://www.ncbi.nlm.nih.gov/pubmed/18157115.

9. Nakagawa, M., Koyanagi, M., Tanabe, K., et al. (2008). Generation of induced pluripotent stem cells without Myc from mouse and human fibroblasts. Nature Biotechnology [Internet] [cited $2011 \mathrm{Jul}$ 17], 26(1), 101-6. Available from: http://www.ncbi.nlm. nih.gov/pubmed/18059259.

10. Stadtfeld, M., Nagaya, M., Utikal, J., Weir, G., Hochedlinger, K. (2008). Induced pluripotent stem cells generated without viral integration. Science (New York, NY) [Internet] [cited 2011 Jul
20], 322(5903), 945-9. Available from: http://www.ncbi.nlm.nih. gov/pubmed/18818365.

11. Ban, H., Nishishita, N., Fusaki, N., et al. (2011). Efficient generation of transgene-free human induced pluripotent stem cells (iPSCs) by temperature-sensitive Sendai virus vectors. Proceedings of the National Academy of Sciences [Internet] [cited 2011 Aug 6], 108(34), 14234-9. Available from: http://www.pub medcentral.nih.gov/articlerender.fcgi? artid=3161531\&tool= pmcentrez\&rendertype $=$ abstract.

12. Okita, K., Nakagawa, M., Hyenjong, H., Ichisaka, T., Yamanaka, S. (2008). Generation of mouse induced pluripotent stem cells without viral vectors. Science (New York, NY) [Internet] [cited 2011 Jul 17], 322(5903), 949-53. Available from: http:// www.ncbi.nlm.nih.gov/pubmed/18845712.

13. Yusa, K., Rad, R., Takeda, J., Bradley, A. (2009). Generation of transgene-free induced pluripotent mouse stem cells by the piggyBac transposon. Nature Methods [Internet] [cited 2011 Aug 29], 6 (5), 363-9. Available from: http://www.pubmedcentral.nih. gov/articlerender.fcgi? artid $=2677165 \&$ tool $=$ pmcentrez $\&$ rendertype $=$ abstract.

14. Anokye-Danso, F., Trivedi, C. M., Juhr, D, et al. (2011). Highly efficient miRNA-mediated reprogramming of mouse and human somatic cells to pluripotency. Cell Stem Cell [Internet] [cited 2011 Jul 6], 8(4), 376-88. Available from: http://www.pubmedcentral. nih.gov/articlerender.fcgi? artid=3090650\&tool=pmcentrez\& rendertype $=$ abstract.

15. Warren, L., Manos, P. D., Ahfeldt, T., et al. (2010). Highly efficient reprogramming to pluripotency and directed differentiation of human cells with synthetic modified mRNA. Cell Stem Cell [Internet] [cited $2011 \mathrm{Jul}$ 18], 7(5), 618-30. Available from: http:// www.ncbi.nlm.nih.gov/pubmed/20888316.

16. Kim, D., Kim, C-H., Moon, J-I., et al. (2009). Generation of human induced pluripotent stem cells by direct delivery of reprogramming proteins. Cell Stem Cell [Internet] [cited 2012 Mar 12], 4 (6), 472-6. Available from: http://www.pubmedcentral.nih. gov/articlerender.fcgi? artid $=2705327 \&$ tool=pmcentrez\& rendertype $=$ abstract.

17. Kuzmenkin, A., Liang, H., Xu, G., et al. (2009). Functional characterization of cardiomyocytes derived from murine induced pluripotent stem cells in vitro. The FASEB Journal: Official publication of the Federation of American Societies for Experimental Biology [Internet] [cited 2011 Jul 7], 23(12), 4168-80. Available from: http://www.ncbi.nlm.nih.gov/pubmed/19703934.

18. Ren, Y., Lee, M. Y., Schliffke, S., et al. (2011). Small molecule Wnt inhibitors enhance the efficiency of BMP-4-directed cardiac differentiation of human pluripotent stem cells. Journal of Molecular and Cellular Cardiology [Internet] [cited $2011 \mathrm{Jul}$ 27], 51(3), 280-7. Available from: http://www.ncbi.nlm.nih.gov/pubmed/ 21569778.

19. Espejel, S., Roll, G. R., McLaughlin, K. J., et al. (2010). Induced pluripotent stem cell-derived hepatocytes have the functional and proliferative capabilities needed for liver regeneration in mice. The Journal of Clinical Investigation [Internet] [cited 2011 Sep 21], 120(9), 3120-6. Available from: http://www.pubmedcentral. nih.gov/articlerender.fegi? artid $=2929736 \&$ tool=pmcentrez $\&$ rendertype $=$ abstract.

20. Hanna, J., Wernig, M., Markoulaki, S., et al. (2007). Treatment of sickle cell anemia mouse model with iPS cells generated from autologous skin. Science (New York, NY) [Internet] [cited 2011 Jun 13], 318(5858), 1920-3. Available from: http:// www.ncbi.nlm.nih.gov/pubmed/18063756.

21. Czepiel, M., Balasubramaniyan, V., Schaafsma, W., et al. (2011). Differentiation of induced pluripotent stem cells into functional oligodendrocytes. Glia [Internet] [cited 2011 Jul 29], 59(6), 88292. Available from: http://www.ncbi.nlm.nih.gov/pubmed/ 21438010. 
22. Wernig, M., Zhao, J-P., Pruszak, J., et al. (2008) Neurons derived from reprogrammed fibroblasts functionally integrate into the fetal brain and improve symptoms of rats with Parkinson's disease. Proceedings of the National Academy of Sciences of the United States of America [Internet] [cited 2011 Sep 20], 105(15), 585661. Available from: http://www.pubmedcentral.nih.gov/article render.fcgi? artid $=2311361 \&$ tool $=$ pmcentrez\&rendertype $=$ abstract.

23. Karumbayaram, S., Novitch, B. G., Patterson, M., et al. (2009). Directed differentiation of human-induced pluripotent stem cells generates active motor neurons. Stem Cells (Dayton, Ohio) [Internet] [cited 2011 Jun 13], 27(4), 806-11. Available from: http:// www.pubmedcentral.nih.gov/articlerender.fcgi?artid=2895909\& tool $=$ pmcentrez\&rendertype $=$ abstract.

24. Olanow, C. W., Kordower, J. H., Freeman, T. B. (1996). Fetal nigral transplantation as a therapy for Parkinson's disease. Trends in Neurosciences [Internet] [cited 2011 Dec 12], 19(3), 102-9. Available from: http://www.ncbi.nlm.nih.gov/pubmed/9054056.

25. Kopyov, O. V., Jacques, D., Lieberman, A., Duma, C. M., Rogers, R. L. Clinical study of fetal mesencephalic intracerebral transplants for the treatment of Parkinson's disease. Cell Transplantation [Internet] [cited 2011 Dec 13], 5(2), 327-37. Available from: http://www.ncbi.nlm.nih.gov/pubmed/8689043.

26. Roybon, L., Hjalt, T., Christophersen, N. S., Li, J-Y., Brundin, P. (2008). Effects on differentiation of embryonic ventral midbrain progenitors by Lmx1a, Msx1, Ngn2, and Pitx3. The Journal of Neuroscience: The Official Journal of the Society For Neuroscience [Internet] [cited 2011 Jul 19], 28(14), 3644-56. Available from: http://www.ncbi.nlm.nih.gov/pubmed/18385323.

27. López-Lozano, J. J., Bravo, G., Brera, B., et al. (1997). Long-term improvement in patients with severe Parkinson's disease after implantation of fetal ventral mesencephalic tissue in a cavity of the caudate nucleus: 5-year follow up in 10 patients. Clinica Puerta de Hierro Neural Transplantation Group. Journal of Neurosurgery [Internet] [cited 2011 Dec 13], 86(6), 931-42. Available from: http://www.ncbi.nlm.nih.gov/pubmed/9171171.

28. Freed, C. R., Greene, P. E., Breeze, R. E., et al. (2001). Transplantation of embryonic dopamine neurons for severe Parkinson's disease. The New England journal of medicine [Internet] [cited 2011 Sep 16], 344(10), 710-9. Available from: http:// www.ncbi.nlm.nih.gov/pubmed/11236774.

29. Devine, M. J., Ryten, M., Vodicka, P., et al. (2011). Parkinson's disease induced pluripotent stem cells with triplication of the $\alpha$ synuclein locus. Nature Communications [Internet] [cited 2011 Aug 23], 2, 440. Available from: http://www.ncbi.nlm.nih.gov/ pubmed/21863007.

30. Nguyen, H. N., Byers, B., Cord, B., et al. (2011). LRRK2 mutant iPSC-derived DA neurons demonstrate increased susceptibility to oxidative stress. Cell Stem Cell [Internet] [cited 2011 Jun 19], 8 (3), 267-80. Available from: http://www.ncbi.nlm.nih.gov/ pubmed/21362567.

31. Chung, S., Shin, B-S., Hwang, M., et al. (2006). Neural precursors derived from embryonic stem cells, but not those from fetal ventral mesencephalon, maintain the potential to differentiate into dopaminergic neurons after expansion in vitro. Stem Cells (Dayton, Ohio) [Internet] [cited 2011 Sep 13], 24(6), 1583-93. Available from: http://www.pubmedcentral.nih.gov/articlerender.fcgi? artid $=2613224 \&$ tool $=$ pmcentrez\&rendertype $=$ abstract.

32. Chung, S., Moon, J-I., Leung, A., et al. (2011). ES cell-derived renewable and functional midbrain dopaminergic progenitors. Proceedings of the National Academy of Sciences of the United States of America [Internet] [cited 2011 Jul 28], 108(23), 9703-8. Available from: http://www.pubmedcentral.nih.gov/articlerender.fcgi? artid $=3111266 \&$ tool $=$ pmcentrez\&rendertype $=$ abstract.

33. Roybon, et al. Effects on differentiation of embryonic ventral midbrain progenitors by Lmx1a, Msx1, Ngn2, and Pitx3. Journal of Neuroscience, 28(14), 3644.
34. Rössler, R., Boddeke, E., Copray, S. (2010). Differentiation of non-mesencephalic neural stem cells towards dopaminergic neurons. Neuroscience [Internet] [cited 2011 Jul 27], 170(2), 417-28. Available from: http:/www.ncbi.nlm.nih.gov/pubmed/ 20643196.

35. Kawasaki, H., Mizuseki, K., Nishikawa, S., et al. (2000). Induction of midbrain dopaminergic neurons from ES cells by stromal cellderived inducing activity. Neuron [Internet] [cited 2011 Sep 21], 28(1), 31-40. Available from: http://www.ncbi.nlm.nih.gov/ pubmed/11086981.

36. Kawasaki, H., Suemori, H., Mizuseki, K., et al. (2002). Generation of dopaminergic neurons and pigmented epithelia from primate ES cells by stromal cell-derived inducing activity. Proceedings of the National Academy of Sciences of the United States of America [Internet] [cited $2011 \mathrm{Nov}$ 13], 99(3), 1580-5. Available from: http://www.pubmedcentral.nih.gov/articlerender.fcgi?artid= $122233 \&$ tool=pmcentrez\&rendertype $=$ abstract.

37. Chambers, S. M., Fasano, C. A., Papapetrou, E. P., Tomishima, M., Sadelain, M., Studer, L. (2009). Highly efficient neural conversion of human ES and iPS cells by dual inhibition of SMAD signaling. Nature Biotechnology [Internet] [cited 2011 Jun 13], 27(3), 27580. Available from: http://www.pubmedcentral.nih.gov/article render.fcgi? artid $=2756723 \&$ tool $=$ pmcentrez\&rendertype $=$ abstract.

38. Fasano, C. A., Chambers, S. M., Lee, G., Tomishima, M. J., Studer, L. (2010). Efficient derivation of functional floor plate tissue from human embryonic stem cells. Cell Stem Cell [Internet] [cited 2011 Sep 13], 6(4), 336-47. Available from: http:// www.ncbi.nlm.nih.gov/pubmed/20362538.

39. Kriks, S., Shim, J-W., Piao, J., et al. (2011). Dopamine neurons derived from human ES cells efficiently engraft in animal models of Parkinson's disease. Nature [Internet] [cited 2011 Nov 6], 480 (7378), 547-51. Available from: http://www.pubmedcentral. nih.gov/articlerender.fegi? artid $=3245796 \&$ tool $=$ pmcentrez $\&$ rendertype $=$ abstract.

40. Zhou, W., Lee, Y. M., Guy, V. C., Freed, C. R. (2009). Embryonic stem cells with GFP knocked into the dopamine transporter yield purified dopamine neurons in vitro and from knock-in mice. Stem Cells (Dayton, Ohio) [Internet] [cited 2011 Jun 13], 27(12), 295261. Available from: http://www.ncbi.nlm.nih.gov/pubmed/ 19750538.

41. Hedlund, E., Pruszak, J., Lardaro, T., et al. (2008). Embryonic stem cell-derived Pitx3-enhanced green fluorescent protein midbrain dopamine neurons survive enrichment by fluorescenceactivated cell sorting and function in an animal model of Parkinson's disease. Stem Cells (Dayton, Ohio) [Internet] [cited 2011 Aug 4], 26(6), 1526-36. Available from: http://www.pubmed central.nih.gov/articlerender.fcgi? artid=2693914\&tool= pmcentrez\&rendertype $=$ abstract.

42. Nunes, I., Tovmasian, L. T., Silva, R. M., Burke, R. E., Goff, S. P. (2003). Pitx3 is required for development of substantia nigra dopaminergic neurons. Proceedings of the National Academy of Sciences of the United States of America [Internet] [cited 2011 Nov 9], 100(7), 4245-50. Available from: http://www.pubmed central.nih.gov/articlerender.fcgi?artid=153078\&tool=pmcentrez\& rendertype $=$ abstract.

43. van den Munckhof, P., Luk, K. C., Ste-Marie, L., et al. (2003). Pitx3 is required for motor activity and for survival of a subset of midbrain dopaminergic neurons. Development (Cambridge, England) [Internet] [cited 2012 Jan 4], 130(11), 2535-42. Available from: http://www.ncbi.nlm.nih.gov/pubmed/12702666.

44. Jacobs, F. M. J., van Erp, S., van der Linden, A. J. A., von Oerthel, L., Burbach, J. P. H., Smidt, M. P. (2009). Pitx3 potentiates Nurr1 in dopamine neuron terminal differentiation through release of SMRT-mediated repression. Development (Cambridge, England) [Internet] [cited $2011 \mathrm{Sep} 20], 136(4), 531-40$. Available from: http://www.ncbi.nlm.nih.gov/pubmed/19144721. 
45. Jacobs, F. M. J., Veenvliet, J. V., Almirza, W. H., et al. (2011). Retinoic acid-dependent and -independent gene-regulatory pathways of Pitx 3 in meso-diencephalic dopaminergic neurons. Development (Cambridge, England) [Internet] [cited 2011 Nov 22], 138 (23), 5213-22. Available from: http://www.ncbi.nlm.nih.gov/ pubmed/22069189.

46. Nirenberg, M. J., Vaughan, R. A., Uhl, G. R., Kuhar, M. J., Pickel, V. M. (1996). The dopamine transporter is localized to dendritic and axonal plasma membranes of nigrostriatal dopaminergic neurons. The Journal of Neuroscience: The Official Journal of the Society For Neuroscience [Internet] [cited 2012 Jan 4], 16(2), 436-47. Available from: http://www.ncbi.nlm.nih.gov/pubmed/ 8551328.

47. Nishino, K., Toyoda, M., Yamazaki-Inoue, M., et al. (2011). DNA methylation dynamics in human induced pluripotent stem cells over time. PLoS genetics [Internet] [cited 2011 Jul 19], 7(5), e1002085. Available from: http://www.pubmedcentral.nih. gov/articlerender.fcgi? artid $=3102737 \&$ tool $=$ pmcentrez $\&$ rendertype $=$ abstract.

48. Ohi, Y., Qin, H., Hong, C., et al. (2011). Incomplete DNA methylation underlies a transcriptional memory of somatic cells in human iPS cells. Nature Cell Biology [Internet] [cited 2011 Jun 13], 13(5), 541-9. Available from: http://www.ncbi.nlm.nih.gov/ pubmed/21499256.

49. Doi, A., Park, I-H., Wen, B., et al. (2009). Differential methylation of tissue- and cancer-specific $\mathrm{CpG}$ island shores distinguishes human induced pluripotent stem cells, embryonic stem cells and fibroblasts. Nature Genetics [Internet] [cited 2011 Jul 17], 41(12), 1350-3. Available from: http://www.pubmedcentral.nih.gov/articlerender.fcgi? artid $=2958040 \&$ tool $=$ pmcentrez\&rendertype $=$ abstract.

50. Maherali, N., Sridharan, R., Xie, W., et al. (2007). Directly reprogrammed fibroblasts show global epigenetic remodeling and widespread tissue contribution. Cell Stem Cell [Internet] [cited 2011 Jul 18], 1(1), 55-70. Available from: http://www.ncbi.nlm.nih.gov/ pubmed/18371336.

51. Rhee, Y-H., Ko, J-Y., Chang, M-Y., et al. (2011). Protein-based human iPS cells efficiently generate functional dopamine neurons and can treat a rat model of Parkinson disease. The Journal of Clinical Investigation [Internet] [cited 2011 Aug 22], 121(6), 2326-35. Available from: http://www.pubmedcentral.nih.gov/ articlerender.fcgi? artid $=3104759 \&$ to ol $=$ pmcentrez\& rendertype $=$ abstract.

52. Soldner, F., Hockemeyer, D., Beard, C., et al. (2009). Parkinson's disease patient-derived induced pluripotent stem cells free of viral reprogramming factors. Cell [Internet] [cited 2011 Jul 18], 136(5), 964-77. Available from: http://www.pubmedcentral.nih.gov/ articlerender.fcgi artid $=2787236 \&$ tool $=$ pmcentrez\& rendertype $=$ abstract.

53. Hargus, G., Cooper, O., Deleidi, M., et al. (2010). Differentiated Parkinson patient-derived induced pluripotent stem cells grow in the adult rodent brain and reduce motor asymmetry in Parkinsonian rats. Proceedings of the National Academy of Sciences of the United States of America [Internet] [cited 2011 Jul 19], 107(36), 15921-6. Available from: http://www.pubmedcentral.nih.gov/articlerender.fcgi? artid $=2936617 \&$ tool $=$ pmcentrez\&rendertype $=$ abstract.

54. Soldner, F., Laganière, J., Cheng, A. W., et al. (2011). Generation of isogenic pluripotent stem cells differing exclusively at two early onset Parkinson point mutations. Cell [Internet] [cited 2011 Jul 17], 146(2), 318-31. Available from: http://www.pubmedcentral. nih.gov/articlerender.fcgi? artid $=3155290 \&$ tool $=$ pmcentre $\& \&$ rendertype $=$ abstract.

55. Vekrellis, K., Xilouri, M., Emmanouilidou, E., Rideout, H. J., Stefanis, L. (2011). Pathological roles of $\alpha$-synuclein in neurological disorders. Lancet Neurology [Internet] [cited 2011 Oct 24], 10
(11), 1015-25. Available from: http://www.ncbi.nlm.nih.gov/ pubmed/22014436.

56. Auluck, P. K., Caraveo, G., Lindquist, S. (2010). $\alpha$-Synuclein: Membrane interactions and toxicity in Parkinson's disease. Annual Review of Cell and Developmental Biology [Internet] [cited 2011 Jul 13], 26, 211-33. Available from: http://www.ncbi.nlm.nih.gov/ pubmed/20500090.

57. Hockemeyer, D., Soldner, F., Beard, C., et al. (2009). Efficient targeting of expressed and silent genes in human ESCs and iPSCs using zinc-finger nucleases. Nature Biotechnology [Internet] [cited 2011 Jun 13], 27(9), 851-7. Available from: http://www.ncbi.nlm. nih.gov/pubmed/19680244.

58. Hockemeyer, D., Wang, H., Kiani, S., et al. (2011). Genetic engineering of human pluripotent cells using TALE nucleases. Nature Biotechnology [Internet] [cited 2011 Jul 15], 29(8), 731-4. Available from: http://www.pubmedcentral.nih.gov/articlerender.fcgi? artid $=3152587 \&$ tool $=$ pmcentre $\&$ rendertype $=$ abstract.

59. Vierbuchen, T., Ostermeier, A., Pang, Z. P., Kokubu, Y., Südhof, T. C., Wernig, M. (2010). Direct conversion of fibroblasts to functional neurons by defined factors. Nature [Internet] [cited 2011 Jul 17], 463(7284), 1035-41. Available from: http://www.pubmedcentral.nih.gov/articlerender.fcgi? artid $=2829121 \&$ tool $=$ pmcentrez\&rendertype $=$ abstract .

60. Pang, Z. P., Yang, N., Vierbuchen, T., et al. (2011). Induction of human neuronal cells by defined transcription factors. Nature [Internet] [cited 2011 Jun 10], 476(7359), 220-3. Available from: http://www.pubmedcentral.nih.gov/articlerender.fcgi?artid= $3159048 \&$ tool $=$ pmcentrez\&rendertype $=$ abstract .

61. Pfisterer, U., Kirkeby, A., Torper, O., et al. (2011). Direct conversion of human fibroblasts to dopaminergic neurons. Proceedings of the National Academy of Sciences of the United States of America [Internet] [cited $2011 \mathrm{Jul} 16], 108(25), 10343-8$. Available from: http://www.pubmedcentral.nih.gov/articlerender.fcgi?artid= 3121829\&tool $=$ pmcentrez\&rendertype $=$ abstract.

62. Caiazzo, M., Dell'anno, M. T., Dvoretskova, E., et al. (2011). Direct generation of functional dopaminergic neurons from mouse and human fibroblasts. Nature [Internet] [cited $2011 \mathrm{Jul} 5$ ], 476 (7359), 224-7. Available from: http://www.ncbi.nlm.nih.gov/ pubmed/21725324.

63. Lee, H-S., Bae, E-J., Yi, S-H., et al. (2010). Foxa2 and Nurr1 synergistically yield A9 nigral dopamine neurons exhibiting improved differentiation, function, and cell survival. Stem Cells (Dayton, Ohio) [Internet] [cited 2011 Sep 13], 28(3), 501-12. Available from: http://www.ncbi.nlm.nih.gov/pubmed/20049900.

64. Lin, W., Metzakopian, E., Mavromatakism, Y. E., et al. (2009). Foxa1 and Foxa2 function both upstream of and cooperatively with Lmxla and Lmx1b in a feedforward loop promoting mesodiencephalic dopaminergic neuron development. Developmental Biology [Internet] [cited $2011 \mathrm{Jul}$ 28], 333(2), 386-96. Available from: http://www.ncbi.nlm.nih.gov/pubmed/19607821.

65. Nakatani, T., Kumai, M., Mizuhara, E., Minaki, Y., Ono, Y. (2010). Lmx 1a and Lmx1b cooperate with Foxa2 to coordinate the specification of dopaminergic neurons and control of floor plate cell differentiation in the developing mesencephalon. Developmental Biology [Internet] [cited 2011 Sep 25], 339(1), 101-13. Available from: http://www.ncbi.nlm.nih.gov/pubmed/20035737.

66. Chung, S., Leung, A., Han, B-S., et al. (2009). Wnt1-lmx1a forms a novel autoregulatory loop and controls midbrain dopaminergic differentiation synergistically with the SHH-FoxA2 pathway. Cell Stem Cell [Internet] [cited 2011 Jul 26], 5(6), 646-58. Available from: http://www.pubmedcentral.nih.gov/articlerender.fcgi? artid $=2788512$ \& tool $=$ pmcentre $\&$ rendertype $=$ abstract.

67. Andersson, E., Tryggvason, U., Deng, Q., et al. (2006). Identification of intrinsic determinants of midbrain dopamine neurons. 
Cell [Internet] [cited 2011 Jun 20], 124(2), 393-405. Available from: http://www.ncbi.nlm.nih.gov/pubmed/16439212.

68. Cai, J., Donaldson, A., Yang, M., German, M. S., Enikolopov, G., Iacovitti, L. (2009). The role of Lmxla in the differentiation of human embryonic stem cells into midbrain dopamine neurons in culture and after transplantation into a Parkinson's disease model. Stem Cells (Dayton, Ohio) [Internet] [cited 2011 Jun 13], 27(1),
220-9. Available from: http://www.ncbi.nlm.nih.gov/pubmed/ 18832589.

69. Kim, J., Su, S. C., Wang, H., et al. (2011). Functional integration of dopaminergic neurons directly converted from mouse fibroblasts. Cell Stem Cell [Internet] [cited 2011 Oct 24], 9(5), 413-9. Available from: http://www.pubmedcentral.nih.gov/articlerender.fcgi? artid $=3210333 \&$ tool $=$ pmcentre $\&$ rendertype $=$ abstract. 